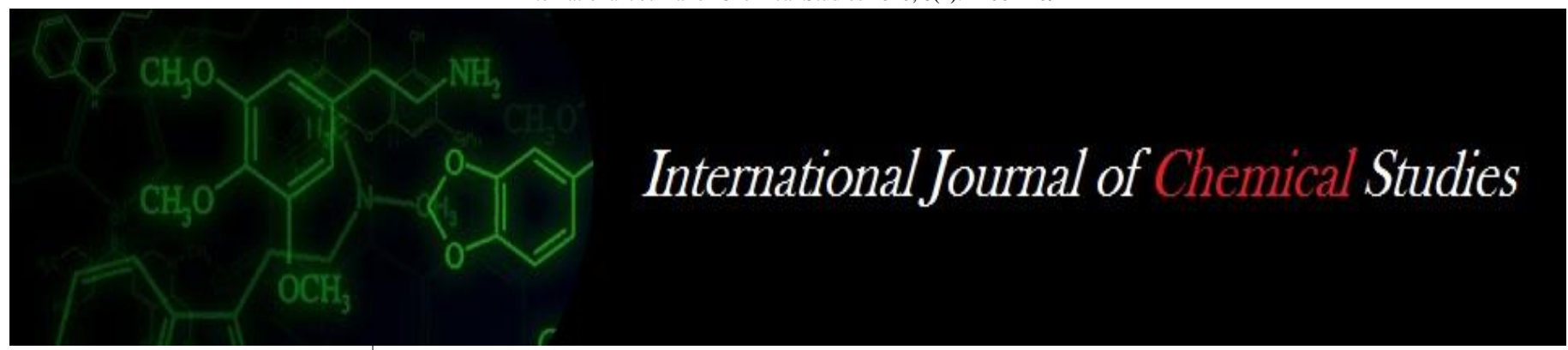

P-ISSN: 2349-8528

E-ISSN: 2321-4902

IJCS 2020; 8(1): 2106-2109

(C) 2020 IJCS

Received: 01-11-2019

Accepted: 03-12-2019

\section{Deepan M}

PG Scholar, Department of Agricultural and Rura

Management, TNAU,

Coimbatore, Tamil Nadu, India

\section{Deepa $\mathbf{N}$}

Assistant Professor (ARM), Agrl College and Research Institute,

TNAU, Madurai, Tamil Nadu, India

\section{Rohini A}

Associate Professor, Department of Agricultural and Rural

Management, TNAU,

Coimbatore, Tamil Nadu, India

\section{Malarkodi M}

Assistant Professor (HRM),

Directorate of ABD, TNAU,

Coimbatore, Tamil Nadu, India

\section{Indumathi VM}

Assistant Professor (ARM), Agrl. College and Research Institute, TNAU,

Kudumiyanmalai, Tamil Nadu, India
Corresponding Author: Deepan M

PG Scholar, Department of Agricultural and Rural

Management, TNAU,

Coimbatore, Tamil Nadu, India

\section{Factors influencing mutual fund investment decisions-factor analysis}

\author{
Deepan M, Deepa N, Rohini A, Malarkodi M and Indumathi VM
}

DOI: https://doi.org/10.22271/chemi.2020.v8.i1ae.8578

\begin{abstract}
Mutual funds become one of an important portal for many retail investors. The investor's investment decision on mutual fund lies upon many factors namely easy liquidity, high flexibility, stability of returns, minimum initial investments, tax benefits and professional management. The product related factors and behaviour related factors were considered for the study. Investor's behaviour may change from period to period even if the other variables influencing the behaviour are held constant. With this context, this study attempts to analyse the influence of behavioural and product related factors on mutual fund investment decisions. Coimbatore city was willfully selected to satisfy the objectives of the study and Purposive sampling technique was employed for data collection from 60 investors of different mutual fund schemes. Principal Component Analysis was employed to analyze the influence of behavioral and product related factors on mutual fund investment decisions. The nine fund behaviour related variables were condensed into two factors namely "external scheme qualities" and "internal scheme qualities". The six product linked variables were analyzed and grouped as two factors which are named as "Reputation" and "Performance".
\end{abstract}

Keywords: Factors, mutual fund investment, decisions-factor

\section{Introduction}

The mutual fund industry in India supplement around 3.2 million new investors to the stake in financial year 2018. The investment decision by the individual investors was considered to be more rational in making investments. Mutual funds become one of an important portal for many retail investors. It is sensible to assume that a typical investor wants not only good return on investment but also to minimize risk. Mutual funds offer such an opening to an investor with feasibly an optimal investment opportunity to invest in diversified and professionally managed basket of securities relatively at a low cost. A mutual fund is the most suitable investment for the retail investors as it offers an opportunity to invest in a diversified, professionally managed portfolio at a relatively low cost. Retail investors are unique and are an immensely heterogeneous group. A large number of investment options are available to retail and institutional investors. Currently there are large numbers of schemes available and the Asset Management Companies (AMCs) compete against one another by launching new products or drifting old ones. Unless mutual fund schemes are tailored to the changing needs, and the AMCs recognize the fund selection behaviour of the investors; survival of funds will be difficult in future.

According to industry experts, the mutual fund industry in India has a huge growth potential and as on $30^{\text {th }}$ January 2019, manages assets worth Rs. 23, 37,134 crores. The AUM (Assets Under Management) of the industry has grown by six-fold in a term of 10 years and this growth is expected to continue in the coming years (www.bankbazaar.com).

The investor's investment decision on mutual fund lies upon many factors namely easy liquidity, high flexibility, stability of returns, minimum initial investments, tax benefits and professional management. The product related factors considered for the study are type of mutual fund scheme, past performance of funds, disclosure of NAV, reputation of the fund manager/ scheme, dividend history, prompt delivery of documents, scheme's expense ratio, entry \& exit load, schemes portfolio, redemption facilities, good customer dealing, prompt settlement, fringe benefits, frequent communication and some of the investing behaviour related factors which considered for the study is public banks mutual fund schemes, sectorbased investments and preferred mode of investment. 
Investor's behaviour may change from period to period even if the other variables influencing the behaviour are held constant. With this context, this study attempts to analyse the influence of behavioural and product related factors on mutual fund investment decisions

\section{Review of Past Studies}

Jyothi and Vijaya (2015) ${ }^{[2]}$ evident that the investors are subjective, in the selection of schemes, by the range factors in terms of the quality of product, quality of sponsors and quality of services. Besides, accessibility to the right people who retain knowledge and skills and are reactive in solving hitches of investors proficiently is the need of an hour. Even in uncertainty stints, steps need to be engaged to mount confidence in the cognizance of the investor and to inspire $\mathrm{him} /$ her to invest in mutual funds.

Sharma and Rekha (2015) ${ }^{[3]}$ study concluded that the main motive behind investment in mutual funds is good return, safety and tax benefit. The research also suggested that the growth schemes and balanced schemes are most preferred in comparison to other open ended and close ended schemes.

Fatima and Khan (2017) ${ }^{[1]}$ study revealed that the past performance is playing the vital role in influencing the investors' decision making. The reputation of the fund manager, portfolio (fund objective) and service quality are the main variables which were preferred by the investors. Hence there is a need to do further research in this area by considering the perception of the investor and secondary market influence on the decision making.

Sudarmathi and Bala (2017) ${ }^{[4]}$ concluded that diversified investment in different investment options, mutual fund plan and duration of investment are playing major role in investing mutual funds.

Varun and Divya (2017) ${ }^{[5]}$ concluded that the unwillingness in investing Mutual Funds can be avoided by promotional activities and also, they added, investors not only consider fundamental analysis but also by their own behaviour, needs and affordability while choosing their investment.

\section{Materials and Methods}

Coimbatore city was willfully selected to satisfy the objectives of the study because there were more than 25 asset management companies playing a major role in financial investments and more number of investors invested in mutual funds. The list of individual investors has been collected from the mutual fund institutions and the individual investors were purposively selected using Purposive sampling technique. The selection of respondents was done among the investors who invested in any one of the mutual fund schemes. Thus, the overall sample size was 60 investors of different mutual fund schemes. Primary data was collected using well-structured interview schedule. Principal Component Analysis was employed to analyze the influence of behavioral and product related factors on mutual fund investment decisions.

\section{Results and Discussion}

The collected data were analyzed using Principal Component Analysis and the results are as follows;

\section{Investors choices are influenced by Fund behavior related factors}

The nine-fund behavior linked variables were analyzed for their level of importance. This analysis discloses that the investor deliberates all the nine variables as vital in their choice of fund/scheme based on fund related qualities. Mean value and the ranks are given in the table 1.

Table 1: Fund behavior linked factors for factor analysis

\begin{tabular}{|c|c|c|c|c|}
\hline S. No & Factors (N = 60) & Mean & SD & Rank \\
\hline 1 & Fund performance record & 4.10 & 0.681 & 3 \\
\hline 2 & Funds reputation or brand name & 3.91 & 0.915 & 6 \\
\hline 3 & Entry and exit load & 3.95 & 0.790 & 5 \\
\hline 4 & Withdrawal facilities & 3.88 & 0.783 & 8 \\
\hline 5 & Minimum initial investment & 4.25 & 0.836 & 2 \\
\hline 6 & Scheme with tax benefits & 3.90 & 0.796 & 7 \\
\hline 7 & Innovativeness of the scheme & 4.31 & 0.624 & 1 \\
\hline 8 & Reputation of the fund manager & 4.05 & 0.871 & 4 \\
\hline 9 & Favorable rating by rating agency & 3.86 & 0.853 & 9 \\
\hline
\end{tabular}

Scale - Highly important as 5; Not at all important as 1 Therefore, to identify the primary fund/scheme selection behavior of the investor, to group the mutual fund investors into specific market segment and to assist the designing of the suitable marketing strategy, Factor analysis under data reduction technique was done using Principal Component Analysis.

Table 2: KMO and Bartlett's test

\begin{tabular}{|c|c|c|}
\hline \multicolumn{2}{|c|}{ KMO and Bartlett's test } & 0.834 \\
\hline Kaiser - Meyer - Olkin Measure of Sampling Adequacy & Approximate Chi-Square & 155.177 \\
\hline Bartlett's Test of Sphericity & df & 36 \\
\hline Sig. & 0.000 \\
\hline
\end{tabular}

Table 3: Total Variance

\begin{tabular}{|c|c|c|c|c|c|c|}
\hline S. No & \multicolumn{3}{|c|}{ Initial Eigen values } & \multicolumn{3}{c|}{ Extraction Sums of Square Loadings } \\
\hline & Total & Percentage of variance & Cumulative percentage & Total & Percentage of variance & Cumulative percentage \\
\hline 1 & 3.858 & 42.869 & 42.869 & 3.858 & 42.869 & 42.869 \\
\hline 2 & 1.159 & 12.876 & 55.745 & 1.159 & 12.876 & 55.745 \\
\hline 3 & 0.784 & 8.713 & 64.459 & & & \\
\hline 4 & 0.759 & 8.430 & 72.889 & & & \\
\hline 5 & 0.666 & 7.399 & 80.288 & & & \\
\hline 6 & 0.626 & 6.960 & 87.247 & & & \\
\hline 7 & 0.454 & 5.045 & 92.293 & & & \\
\hline 8 & 0.381 & 4.229 & 96.522 & & & \\
\hline 9 & 0.313 & 3.478 & 100.000 & & & \\
\hline
\end{tabular}

Extraction Method: Principal Component Analysis 
Table 4: Rotated Component Matrix for various fund qualities

\begin{tabular}{|c|c|c|c|}
\hline S. No & Factors & $\mathbf{1}$ & $\mathbf{2}$ \\
\hline 1 & Fund based performance record & 0.832 & 0.021 \\
\hline 2 & Funds based reputation or brand name & 0.706 & 0.372 \\
\hline 3 & Entry and exit load & 0.769 & 0.270 \\
\hline 4 & Withdrawal facilities & 0.715 & 0.235 \\
\hline 5 & Minimum initial investment & 0.218 & 0.643 \\
\hline 6 & Scheme with tax benefits & 0.298 & 0.617 \\
\hline 7 & Innovativeness of the scheme & 0.079 & 0.724 \\
\hline 8 & Reputation of the fund manager & 0.308 & 0.612 \\
\hline 9 & Favourable rating by rating agency & 0.367 & 0.626 \\
\hline
\end{tabular}

Factor analysis was conducted to have better understanding of data. From the table 2 it is realized that the approximate chisquare statistic is 155.177 with 36 degrees of freedom which is significant at 0.05 levels. The Kaiser-Meyer-Olkin Measure of Sampling Adequacy statistic of (0.834) is also large (>0.5). Therefore, factor analysis deliberated as a suitable technique for further analysis of data. With Kaiser Normalization, on the basis of Varimax Rotation, two factors have emerged. It is clear that from table 3, two factors were elucidating about $55.745 \%$ of variance. Every single factor is organized of all those variables that have factor loadings greater than or equal to 0.5 as shown in Table 3 . The newly condensed factors are named as external scheme qualities and internal scheme qualities and the same has described below in the table 4 .

Factor 1 is regarded as "External scheme qualities". It composed of 4 items: Fund performance record, Entry and exit load, Withdrawal facilities and Funds reputation or brand name. Factor 2 is called "Internal scheme qualities" it composed of 5 items, minimum initial investment, innovativeness of the scheme, favorable rating by rating agency, reputation of the fund manager and scheme with tax benefits. The condensed two factors are significant as they have qualities that are rated significant with a mean score above and around 4. A study of Jyothi and Vijaya (2015) ${ }^{[2]}$ also evident that the investors are subjective, in choosing the mutual fund schemes, through the range of factors in terms of the quality of product, quality of sponsors and quality of services.

Table 5: Factors and behavioral qualities Mean and Standard Deviations

\begin{tabular}{|c|c|c|c|c|}
\hline Factor & Percentage of variance & Behavioral qualities & Mean & SD \\
\hline \multirow{4}{*}{ External scheme qualities } & \multirow{4}{*}{42.869} & Fund based performance record & 4.10 & 0.681 \\
\hline & & Entry and exit load & 3.95 & 0.790 \\
\hline & & Funds based reputation or brand name & 3.91 & 0.915 \\
\hline & & Withdrawal facilities & 3.88 & 0.783 \\
\hline \multirow{5}{*}{ Internal scheme qualities } & \multirow{5}{*}{12.876} & Innovativeness of the scheme & 4.31 & 0.624 \\
\hline & & Minimum initial investment & 4.25 & 0.836 \\
\hline & & Reputation of the fund manager & 4.05 & 0.871 \\
\hline & & Scheme with tax benefits & 3.90 & 0.796 \\
\hline & & Favorable rating by rating agency & 3.86 & 0.853 \\
\hline
\end{tabular}

Scale - Highly important as 5; Not at all important as 1

\section{Investors selections are influenced by product related} factors

The six product linked variables were analyzed for their significance. The analysis discloses that the investor deliberates all the six variables as significant in their choice of mutual fund scheme based on sponsor linked qualities. Mean value and the ranks are given in the Table 5.

Table 6: Product sponsor linked qualities based on factor analysis

\begin{tabular}{|c|c|c|c|c|}
\hline S. No & Factors $(\mathbf{N}=\mathbf{6 0})$ & Mean & SD & Rank \\
\hline 1 & Reputation of sponsoring firm & 3.80 & 0.732 & 5 \\
\hline 2 & Recognized brand name & 3.90 & 0.796 & 3 \\
\hline 3 & Well-developed agency and network & 3.63 & 0.901 & 6 \\
\hline 4 & Sponsor's expertise in managing money & 4.05 & 0.872 & 2 \\
\hline 5 & Sponsor has well-developed research infrastructure & 3.90 & 0.915 & 4 \\
\hline 6 & Sponsor's past performance in risk and returns & 4.31 & 0.624 & 1 \\
\hline
\end{tabular}

Scale - Highly important as 5; Not at all important as 1

To recognize the product sponsor linked qualities, that influence the investor's mutual fund scheme selection, factor analysis was employed. Table 6 displays the result of KMO and Bartlett's test. The Kaiser-Meyer-Olkin Measure of
Sampling Adequacy statistic (0.776) is also greater than 0.5. Therefore, factor analysis under data reduction is deliberated as a suitable technique for further analysis of data.

Table 7: KMO and Bartlett's Test with approximate Chi-Square

\begin{tabular}{|c|c|c|}
\hline \multicolumn{2}{|c|}{ KMO and Bartlett's test } & 0.776 \\
\hline Kaiser-Meyer-Olkin Measure of Sampling Adequacy & Approximate Chi-Square & 69.556 \\
\hline Bartlett's Test of Sphericity & df & 15 \\
\hline Sig. & 0.000 \\
\hline
\end{tabular}


Table 8: Total Variance

\begin{tabular}{|c|c|c|c|c|c|c|}
\hline S. No & \multicolumn{2}{|c|}{ Initial Eigen values } & \multicolumn{3}{c|}{ Extraction Sums of Square Loadings } \\
\hline & Total & Percentage of variance & Cumulative percentage & Total & Percentage of variance & Cumulative percentage \\
\hline 1 & 2.644 & 44.071 & 44.071 & 2.644 & 44.071 & 44.071 \\
\hline 2 & 0.914 & 15.240 & 59.310 & 0.914 & 15.240 & 59.310 \\
\hline 3 & 0.909 & 15.145 & 74.455 & & & \\
\hline 4 & 0.548 & 9.140 & 83.595 & & & \\
\hline 5 & 0.533 & 8.878 & 92.473 & & & \\
\hline 6 & 0.452 & 7.527 & 100.00 & & & \\
\hline
\end{tabular}

Extraction Method: Principal Component Analysis

Table 9: Rotated Component Matrix for Various product sponsor qualities

\begin{tabular}{|c|c|c|c|}
\hline S. No & Factors & $\mathbf{1}$ & $\mathbf{2}$ \\
\hline 1 & Reputation of sponsoring firm & 0.806 & 0.127 \\
\hline 2 & Recognized brand name & 0.699 & 0.394 \\
\hline 3 & Sponsor's well-developed agency and network & 0.709 & 0.058 \\
\hline 4 & Sponsor's expertise in managing money & 0.396 & 0.573 \\
\hline 5 & Sponsor's well-developed research infrastructure & 0.409 & 0.620 \\
\hline 6 & Sponsor's past performance in risk and returns & 0.068 & 0.837 \\
\hline
\end{tabular}

Table 7 explains the total variance. Based on the eigen value the study surmises that condensed two factors of sponsor qualities together subsidize to 59.310 percent. With Kaiser Normalization and on the basis of Varimax Rotation, 2 sponsor linked factors were emerged after condensation of various qualities. Factor 1 accounts for variance of 44.071 percent and factor 2 accounts for variance of 15.240 percent and all organized they explain 59.310 of variance. The recognized factors with the related qualities and factor loadings were given in the Table 8. Every single factor is organized of all those product sponsor qualities which have factor loadings greater than or equal to 0.5. Fatima and Khan (2017) ${ }^{[1]}$ results revealed that the past performance is playing the vital role in influencing the investors' decision making.

\section{The two factors named as given under are}

1. Reputation: Recognized brand name, sponsor's welldeveloped agency and network and reputation of sponsoring firm.

2. Performance: Sponsor expertise in managing money, sponsor's well-developed research infrastructure and sponsor's past performance in risk and returns.

Table 10: Sponsor and product related factors selection

\begin{tabular}{|c|c|c|c|c|}
\hline Factor & $\%$ variance & Factors & Mean & SD \\
\hline \multirow{3}{*}{ Reputation } & \multirow{3}{*}{44.071} & Recognized brand name & 3.90 & 0.796 \\
\hline & & Reputation of sponsoring firm & 3.80 & 0.732 \\
\hline & & Sponsor's well-developed agency and network & 3.63 & 0.901 \\
\hline \multirow{3}{*}{ Performance } & \multirow{3}{*}{15.240} & Sponsor's past performance in risk and returns & 4.31 & 0.624 \\
\hline & & Sponsor expertise in managing money & 4.05 & 0.872 \\
\hline & & Sponsor's well-developed research infrastructure & 3.90 & 0.915 \\
\hline
\end{tabular}

Scale - Highly important as 5; Not at all important as 1

\section{Conclusion}

The nine-fund behavior linked variables were analyzed for their level of importance. This analysis discloses that the investor deliberates all the nine variables as vital in their choice of fund/scheme based on fund related qualities. Two factors were elucidating about $55.745 \%$ of variance. Every single factor is organized of all those variables that have factor loadings greater than or equal to 0.5. The newly condensed factors are named as external scheme qualities and internal scheme qualities. The condensed two factors are significant as they have qualities that are rated significant with a mean score above and around 4. A study of Jyothi and Vijaya (2015) ${ }^{[2]}$ also evident that the investors are subjective, in choosing the mutual fund schemes, through the range of factors in terms of the quality of product, quality of sponsors and quality of services.

The six product linked variables were analyzed for their significance. The analysis discloses that the investor deliberates all the six variables as significant in their choice of mutual fund scheme based on sponsor linked qualities. With Kaiser Normalization and on the basis of Varimax Rotation, 2 sponsor linked factors named as "Reputation" and "Performance" were emerged after condensation of various qualities. Fatima and Khan (2017) ${ }^{[1]}$ revealed that the past performance is playing the vital role in influencing the investors' decision making.

\section{References}

1. Fatima, Zertaj, Mohd Akbar Ali Khan. A Study of Behavioural Factors Influence on Investment Decision in Mutual Funds-Evidence in Public and Private Banks Mutual Funds. Sumedha Journal of Management. 2017; 6 (2):62-74.

2. Jyothi, Vijaya N. Factors that Influencing the Mutual Fund Investors for Fund/Scheme Selection (With Special Reference to Visakhapatnam), IPE Journal of Management. 2015; 5(1):43.

3. Sharma, Rekha. Behaviour of Mutual Fund investors towards investment option: Mutual Fund." Journal of Management Research and Analysis. 2015; 2(2):162-168.

4. Sudarmathi J, Bala N. A Study on Investors Behaviour Towards Mutual Fund." International Journal of Advance Research and Innovative Ideas in Education IJARIIE. 2017; 3(5).

5. Varun M, Divya P. A Behavioural Study on Influence and Decision Making of Mutual Fund Investors. J Advances in Bus. Management. 2017; 3(03):145-151. 